\title{
APENDICITE AGUDA MIMETIZANDO ESCROTO AGUDO: relato de caso
}

Allyne Capanema GONÇALVES ${ }^{1}$

Marcus Vinícius Capanema GONÇALVES²

${ }^{1}$ Estudante de medicina na Universidade Federal de Minas Gerais UFMG - Belo Horizonte (MG), Brasil.

${ }^{2}$ Cirurgião Geral pelo Hospital das Clínicas da UFMG - Belo Horizonte (MG), Brasil.

Recebido em: 28/05/2016 - Aprovado em: 13/08/2016 - Disponibilizado em: 18/12/2016

\begin{abstract}
RESUMO
Apendicite aguda é a doença cirúrgica do abdome mais comum na prática clínica, acometendo principalmente adultos jovens. Tem um curso rápido e, se não diagnosticada precocemente, é fatal. Possui uma ampla variedade de apresentações clínicas, secundárias à variação anatômica do apêndice cecal em cada indivíduo. Sua apresentação como escroto agudo e abscesso escrotal é bastante rara e atípica, ocorrendo principalmente em pacientes jovens, do sexo masculino, com túnica vaginalis patente.
\end{abstract}

Palavras-chave: apendicite. Apendicite aguda. Escroto agudo. Abscesso.

\section{ABSTRACT}

Acute appendicitis is the most common surgical disease of the abdomen in clinical practice, that mainly affects young adults. It has a fast course and if not diagnosed early, is fatal. It has a wide variety of clinical presentations, secondary to anatomical variation of the appendix in each individual. It's presentation as acute scrotum and scrotal abscess is very rare and unusual, occurring mainly in young patients, male, with patent vaginalis tunic.

Keywords: appendicitis. Acute Appendicitis. Acute scrotum. Abscess.

\section{INTRODUÇÃO}

Apendicite aguda é a causa mais frequente de abdome agudo cirúrgico no mundo, sendo que aproximadamente $8 \%$ da população ocidental desenvolverá essa doença em algum momento de sua vida, com incidência máxima entre 10 e 30 anos de idade $(1,2)$.

$\mathrm{Na}$ embriologia, o apêndice aparece em torno da $8^{\mathrm{a}}$ semana de gestação, não tendo função conhecida em adultos, apesar de especulações sobre seu papel no sistema imunológico pela presença de folículos linfoides em sua submucosa (1). Seu comprimento varia de 2 a $20 \mathrm{~cm}$, média de $9 \mathrm{~cm}$, com base localizada na convergência das tênias ao longo da face anterior do ceco. Porém, sua ponta possui localização variada, sendo pélvica em 30\% da população (3).

O pequeno diâmetro da luz do apêndice em relação ao seu comprimento favorece sua obstrução, seja por fecalito, hiperplasia linfoide, sementes, parasitas ou neoplasia. Dessa forma, acredita-se que a obstrução da sua luz seja a maior causa de apendicite aguda (3). Tal obstrução provoca supercrescimento bacteriano, secreção continuada de muco e 
distensão intraluminal, com subsequente isquemia mucosa, podendo evoluir para gangrena e perfuração (1). Quando ocorre perfuração, essa normalmente acontece com 48 horas de processo inflamatório e é rapidamente bloqueada pelos órgãos e tecidos adjacentes. Raramente ocorre perfuração livre do apêndice na cavidade abdominal com peritonite, choque séptico e múltiplos abscessos intraperitoneais (1).

A apendicite aguda tem natureza polimicrobiana, sendo frequentemente isoladas Escherichia coli (70\%), Strptococcusviridans (43\%), espécies de Bacterioides (80\%) e Pseudomonas (18\%) (4).

Sua apresentação inicial pode ser muito variável, sendo o quadro clínico típico iniciado por dor abdominal difusa, seguida de hiporexia e náuseas. Vômitos esporádicos podem ocorrer. A dor posteriormente se localiza em quadrante inferior direito do abdome e o paciente desenvolve febre e leucocitose. Embora a maioria dos pacientes desenvolva íleo adinâmico, ocasionalmente pode ocorrer diarreia. Sintomas urinários podem estar associados com a possível localização retrocecal do apêndice (1).

O diagnóstico pode ser confirmado por ultrassonografia abdominal na grande maioria do casos, em que se evidencia apêndice espessado ( $7 \mathrm{~mm}$ ou mais no diâmetro ânteroposterior), estrutura luminal não compressível e de paredes espessadas (lesão em alvo), ou presença de apendicolito. A tomografia computadorizada tem maior acurácia no diagnóstico, sendo frequentemente utilizada em apresentações atípicas e idosos (1).

O diagnóstico diferencial pode incluir quase todas as causas de dor abdominal. Pela sua alta frequência, a apendicite aguda nunca deve ser colocada abaixo da segunda opção na lista de hipóteses diagnósticas $(1,5)$. Os principais diagnósticos diferenciais incluem intussuscepção, diverticulite de Meckel, gastroenterite aguda, linfoadenite mesentérica (crianças), pielonefrite, colite, diverticulite, doença inflamatória pélvica, abscesso tuboovariano, cisto ovariano roto e gravidez ectópica (adultos). A videolaparoscopia diagnóstica tem sido cada vez mais usada em casos duvidosos, mulheres em idade fértil e obesos.

O tratamento da apendicite aguda é cirúrgico, pela apendicectomia. No caso de apendicite não complicada, uma dose única de antibiótico pré-operatório cobrindo a microbiota colônica é suficiente (6). Nos casos de perfuração ou gangrena, deve-se manter antibiótico terapia venosa no pósoperatório (7). A maioria dos pacientes com apendicite não complicada recebe alta hospitalar em 24 horas.

Pacientes com apendicite perfurada podem apresentar-se sépticos, necessitando ressuscitação e estabilização antes do 
procedimento cirúrgico. Já os que se apresentam com abscesso, podem requerer tratamento clínico prévio. Abscessos pequenos em pacientes estáveis podem ser conduzidos com antibioticoterapia venosa e apendicectomia com intervalo. Abscessos maiores $(4 \mathrm{a} 6 \mathrm{~cm})$ em pacientes febris devem ser drenados, por via percutânea ou transretal, e a apendicectomia realizada posteriormente, cerca de 6 semanas após o processo inflamatório inicial $(8,9)$.

Pacientes idosos sempre devem ser submetidos à colonoscopia após o procedimento (2-4 semanas), pelo risco de neoplasia de cólon, identificada em aproximadamente $5 \%$ dos casos (9).

A principal complicação pós apendicectomia é a infecção de ferida operatória, apresentando baixa morbidade (10). Outras complicações, pouco frequentes, são obstrução intestinal e fístulas. (11).

\section{RELATO DE CASO}

Paciente do sexo masculino, 18 anos, previamente hígido, com relato de dor abdominal difusa, febre e hiporexia iniciada há 4 dias. Atendido em outro serviço, recebendo analgesia e liberado para casa. Dois dias depois, iniciou dor testicular à direita, intensa, associado a hiperemia e edema local importantes, febre, dor abdominal em região hipogástrica e náuseas sem vômitos. Hábito intestinal regular.
Admitido com sinais de sepse - febril, com taquicardia e taquipnéia. Edema testicular importante à direita, com hiperemia, calor local e flutuação. Exames laboratoriais evidenciaram aumento importante de escórias nitrogenadas e contagem de leucócitos normal. Iniciado suporte intensivo e antibioticoterapia. Realizado ultrassonografia de escroto que evidenciou vascularização de ambos os testículos preservada, presença de edema e infiltrado de subcutâneo e fáscias musculares em topografia de parede abdominal e região inguinal.

Levado ao bloco cirúrgico com hipótese diagnóstica de gangrena de Fournier, com origem em provável escroto agudo.

À exploração do escroto, identificado testículo direito de aspecto normal, mas túnica Dartos necrosada, associado a secreção purulenta peritesticular. Exploração do canal inguinal direito evidenciou necrose de tecido conjuntivo e comunicação ampla com cavidade abdominal. Sem alterações à exploração do testículo esquerdo.

Optado por laparotomia exploradora, evidenciando apêndice retrocecal com sinais de apendicite perfurada, associado a extensa necrose de parede abdominal em retroperitônio, à direita da veia cava inferior, que se estendia até duodeno. Pequena quantidade de líquido purulento em fossa ilíaca direita e entre alças intestinais. Apesar dos achados, todas as alças intestinais 
encontravam-se de bom aspecto, sem comprometimento. Realizado apendicectomia e desbridamento de tecidos desvitalizados, assim como lavagem exaustiva da cavidade abdominal e escroto. Paciente deixado em laparostomia, devido à edema importante de alças intestinais, com drenos de penrose em principais lojas abdominais e escroto.

O paciente permaneceu em CTI por 15 dias, desenvolvendo complicações pós operatórias infecciosas como pneumonia, insuficiência respiratória, abscesso intra-abdominal, infecção fúngica sistêmica e desnutrição, tratados com antibioticoterapia sistêmica, drenagem da cavidade abdominal e suporte nutricional. Evoluiu sem outras intercorrências significativas, recebendo alta no $44^{\circ}$ dia de pós operatório, com abdome fechado. Exame de anátomo-patológico confirmou apendicite aguda supurada.

\section{DISCUSSÃO}

A relação entre o escroto e a cavidade abdominal já é bem conhecida.

O escroto se desenvolve como parte da cavidade abdominal, e o processo vaginallis permanece patente em aproximadamente 80 90\% dos recém nascidos, diminuindo para aproximadamente $20 \%$ em adultos (12).

A perfuração evoluindo com abscesso ocorre em 3-9\% dos pacientes com apendicite aguda, principalmente em diagnósticos tardios, cada vez menos frequentes atualmente pelo acesso da população à assistência médica e métodos propedêuticos acurados. A formação do abscesso ocorre principalmente na pelve, entre as alças intestinais e no espaço subfrênico (12).

O escroto como local de formação de abscesso secundário à apendicite aguda é bastante raro. Revisões na literatura e relatos de casos mostram que esse processo acomete principalmente crianças e adolescentes, preferencialmente do sexo masculino, com a túnica vaginal patente, também podendo ocorrer como complicação pós operatória de apendicectomia $(12,13,14,15,16)$.

\section{CONCLUSÃO}

Apesar de rara, apendicite aguda pode se manifestar como abscesso em escroto ou com aparência de um escroto agudo, mimetizando torção testicular ou hérnia inguinal encarcerada, principalmente em crianças. Isso pode retardar o diagnóstico de apendicite aguda, ou o mesmo pode ser feito no intraoperatório, como o caso relatado neste trabalho.

Sendo o escroto agudo e apendicite aguda doenças muito frequentes na emergência cirúrgica, deve-se ter um alto nível de suspeita antes da confirmação dessa complicação. Ainda, apendicite aguda deve ser mantida como uma das principais hipóteses diagnósticas em caso de dor abdominal em 
adultos jovens, visando diagnóstico e tratamento precoces dessa enfermidade que, se postergado, pode ser fatal.

\section{REFERÊNCIAS}

1. Sabiston Textbook of Surgery, 18th ed; Chap. 49, Appendicitis.

2. Addiss DG, Shaffer N, Fowler BS, et al: The epidemiology of appendicitis and appendectomy in the United States. Am J Epidemiol 132:910-925, 1990

3.Prystowky JB, Pugh CM, Nagle AP: Current problems in surgery: Appendicitis. CurrProblSurg 2005.

4. Bennion RS, Thompson JE: Appendicitis. In Fry DE (ed): Surgical Infections. Boston, Little Brwn, 1995, pp 241 - 250.

5. Silen W: 20. New York: Oxford University Press, 2000.

6. Anderson BR, Kallehave FL, Andersen HK: Antibiotics versus placebo for prevention of postoperative infection after appendicectomy. Cochrane Database Syst Rev 2005.

7. Townfigh S, Chen F, Mason R, et al: Laparoscopic appendectomy significantly reduces length of stay for perforated appendicitis. SurgEndosc 2006.

8. Sudakoff GS, Lundeen SJ, Otterson MF: Transrectal and transvaginalsonographic intervention of infected pelvic fluid collections: A complete approach. Ultrasound Q 2005.

9. Lai HW, Loong CC, Chiu JH, et al: interval appendectomy after conservative treatment of an aooendiceal mass. World J Surg 2006

10. So JB, Chiong EC, Chiong E, et al: Laparoscopic appendectomy for perforated appendicitis. World J Surg 2002

11. Anderson RE: Small bowel obstruction after appendectomy. Br J Surg 2001

\section{TERMO DE CONSENTIMENTO}

Termo de consentimento por escrito foi obtido do paciente para publicação desse relato de caso.

12. Saleem, MM: Scrotal abscess as a complication of perforated appendicitis: a case report and review of the literature. Cases Journal 2008, 1:165

13. Shmit PJ, Hiyama DT, Swisher SG, Bennion RS, Thmpson JE: Analysis of risk factors of post appendectomy intraabdominal abscess. J AM CollSurg 1994, 179: 721-726

14. Friedman SC, Sheynkin YR: acute scrotal symptoms due to perforated appendicitis in children: case report and review of the literature. Pediatric Emerg Care 1995, 11 : 181-182

15. Avelar DT, Rayfield MM: acute appendicitis presenting as a scrotal mass. Jornal of Pediatric Surgery 1976, 11(1): 91-92

16. Ibrahim AH, et al: scrotal appendicitis mimicking acute testicular torsion in a neonate. Ann Saudi Med 2000 20(1): 55-56. 